\title{
NOTES ON THE INDO-AUSTRALIAN ANTS OF GENUS SIMOPONE FOREL (HYMENOPTERA-FORMICIDAE) ${ }^{1}$
}

\author{
By Robert W. Taylor \\ Biological Laboratories, Harvard University
}

I recently discussed a Philippine specimen of Simopone which was tentatively identified as $S$. bakeri Menozzi (Taylor, I965: 6). Subsequent examination of the bakeri holotype has shown the Philippine specimen to be representative of a new species, which is described below, along with diagnostic notes on the bakeri type. Three species of Simopone are now known from the Indo-Australian area. All are represented only by their worker holotypes. They are similar in habitus, and constitute a compact and undoubtedly closely related complex within this predominantly African cerapachyine genus. The generic diagnosis presented earlier (Taylor, loc. cit.) needs no modification at this point.

\section{Simopone chapmani sp. $\mathrm{n}$.}

Type locality. PHILIPPINE ISLANDS: Negros: Horns of Negros, $3600 \mathrm{ft}$. The unique worker holotype was collected, presumablv in rain forest, by the late Dr. James W. Chapman, for whom this species is named.

Type deposition. Museum of Comparative Zoology, Harvard University (Type No. 3I199).

Description. Dimensions (in $\mathrm{mm}$ ) : aggregate total length (TL) ca. 5.0; head length at midline (HL) $0.9 \mathrm{I}$; maximum head width $(\mathrm{HW})$ 0.68; cephalic index $(\mathrm{HW} \times \mathrm{ro0} / \mathrm{HL}) \quad$ (CI) 75 ; maximum eye diameter 0.30 ; ocular index (eye diameter $\times$ I00/HW) (OI) 44 ; minimum interocular distance 0.34 ( I.I $4 \times$ eye diameter); PW 0.55 ; WL I.2; petiolar node length at midline 0.68 ; maximum petiolar node width 0.56 ; postpetiolar length at midline o.64; maximum postpetiolar width $0.6 \mathrm{I}$. Generally similar to the New Guinean $S$. gressitti Taylor, and agreeing with its original description (Taylor, 1965, Breviora 22I: 3), except in the following characters:

\footnotetext{
${ }^{1}$ Research supported by U. S. National Science Foundation Grant No. GB 1634.

The Simopone bakeri Menozzi holotype, discussed here, was generously loaned for study by Prof. Dr. Guido Grandi, Istituto di Entomologia. Universita degli studi, Bologna, Italy.

Manuscript received by the editor January 19, 1966.
} 
I. Smaller size, with narrower head and proportionately large eyes, which are less widely separated relative to their maximum diameter; postpetiole slightly longer than broad in dorsal view (length 1.05 $\times$ width). (The relevant dimensions of gressitti are: TL ca. $6.4 \mathrm{~mm}$; CI 8I ; OI 38; eyes separated by $\mathrm{I} .53 \times$ their maximum diameter; postpetiole length $0.70 \mathrm{~mm}$, width $0.75 \mathrm{~mm}-$ length $0.93 \times$ width.)

2. Transverse occipital carina lacking distinct ribs along its anterior edge.

3. Lateral suturation of mesosoma complete, but less distinct. Transverse ribbing vestigial on dorsal promesonotal suture and lacking on dorsal mesometanotal suture.

4. Transverse anterior petiolar carina without ribs.

5. Sides of postpetiole, in dorsal view, almost parallel, very feebly divergent posteriorly.

6. Body entirely smooth and shining, except for some vestigial fine longitudinal striae on frontal carinae, and scaly microsculpture on sides of pronotum and propodeum, and on metepisternal areas.

7. Post-cephalic ground pilosity more abundant. Very fine short reclinate to suberect hairs scattered on dorsum of mesosoma, most abundant on sides of propodeal dorsum. Similar pilosity moderately abundant on dorsa of petiole and postpetiole. Single, more erect, but barely longer hairs at midlength of each frontal carina and above each eye, but not elsewhere. No subpetiolar "brush" developed; only 2 hairs break the subpetiolar profile.

The mandibular dentition is worn but was probably originally like that of bakeri, as described by Menozzi. The legs are damaged; so details of the tibial and tarsal armament are not known.

Relationships. See below under S. bakeri.

\section{Simopone bakeri Menozzi}

Simopone bakeri Menozzi, I926, Atti Soc. Nat. Mat. Modena, (6) 4:92 (1925), worker. Type locality: Singapore.

The notes below are based on the unique holotype, which has the following dimensions (in $\mathrm{mm}$, see preceding description for explanation of symbols): TL ca. 5.6; HL I.00; HW 0.65 ; CI 65; maximum eye diameter 0.32 ; OI 49 ; minimum interocular distance 0.32 (equal to eye diameter); PW 0.58; WL 1.36; petiolar node length at midline 0.72 ; maximum petiolar node width 0.62 ; postpetiolar length at midline 0.73 ; maximum width of postpetiole 0.65 . Close to chapmani and gressitti, and agreeing with the original description of the latter, except in the following characters: 
I. Smaller size (about as in chapmani), with much narrower head and proportionately much larger eyes, which are less widely separated relative to their maximum diameter; postpetiole distinctly longer than broad in dorsal view (length I.12 $\times$ width).

2. Anterior clypeal border strongly biconcave in frontal view, with a distinct median anterior tooth. mani.

3. Transverse occipital and anterior petiolar carinae as in chap-

4. Lateral mesosomal suturation weaker, as in chapmani. Dorsal promesonotal suture distinctly transversely ribbed; mesometanotal suture lacking on mesosomal dorsum.

5. Sides of postpetiole as in chapmani, almost parallel in dorsal view.

6. Sculpturation generally as in chapmani, but scaly microsculpture lacking on sides of pronotum, which are smooth and shining.

7. Vestiture much more abundant than in either gressitti or chapmani. Moderately long reclinate to sub-erect hairs fairly abundant on head, those at center of frons shortest and least abundant, those along frontal carinae more erect, a single more elongate hair above each eye. Dorsa of mesosoma, petiole and postpetiole with similar, but somewhat longer pilosity, least abundant on disc of pronotum, best developed on propodeum and petiole. Single longer hairs on pronotal humeri, on petiole slightly behind its anterior corners, and dorso-laterally at about mid-length of postpetiole. Anterior gastric pilosity slightly less abundant and shorter than that of nodes, several more elongate hairs laterally, apex surrounded by long arched hairs. The subpetiolar process is partly obscured by glue; it appears that about IO-12 long hairs normally break its ventral profile; they do not form a regular brush-like series as in gressitti.

Relationships. S. bakeri is more similar, and probably more closely related to chapmani than to gressitti. It is easily distinguished from chapmani by the cephalic and ocular proportions, the structure of the anterior clypeal border, and the more abundant vestiture. These three species form an apparently morphoclinal sequence (bakeri $\rightarrow$ chapmani $\rightarrow$ gressitti) in various characters, including decrease in relative size of the eyes (i.e. OI), and increase in relative head width (i.e. CI), in the spacing of the eyes relative to their maximum diameter, and in the width of the postpetiolar dorsum relative to its length. Reduction and specialization of the pilosity also follow this sequence. $S$. bakeri appears to have the most primitive habitus and probably most resembles the ancestral Indo-Australian stock, except perhaps for its possession of a median clypeal tooth, and the lack of a dorsal mesometanotal suture. 


\section{REFERENCE}

TAYLOR, R. W.

1965. New Melanesian ants of the genera Simopone and Amblyopone (Hymenoptera-Formicidae) of Zoogeographic significance. Breviora, 221: 1-11 (pp. 1-6). 

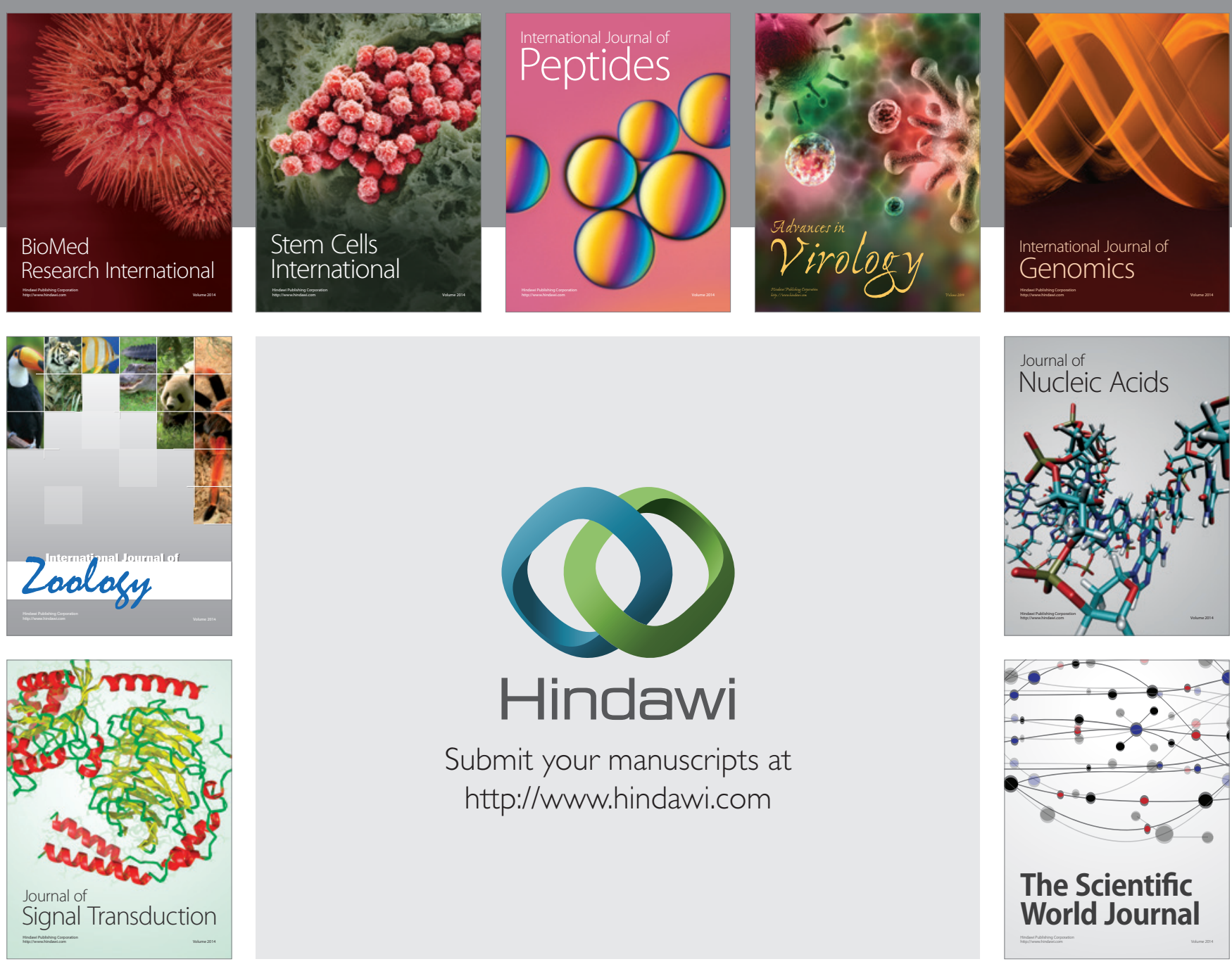

Submit your manuscripts at

http://www.hindawi.com
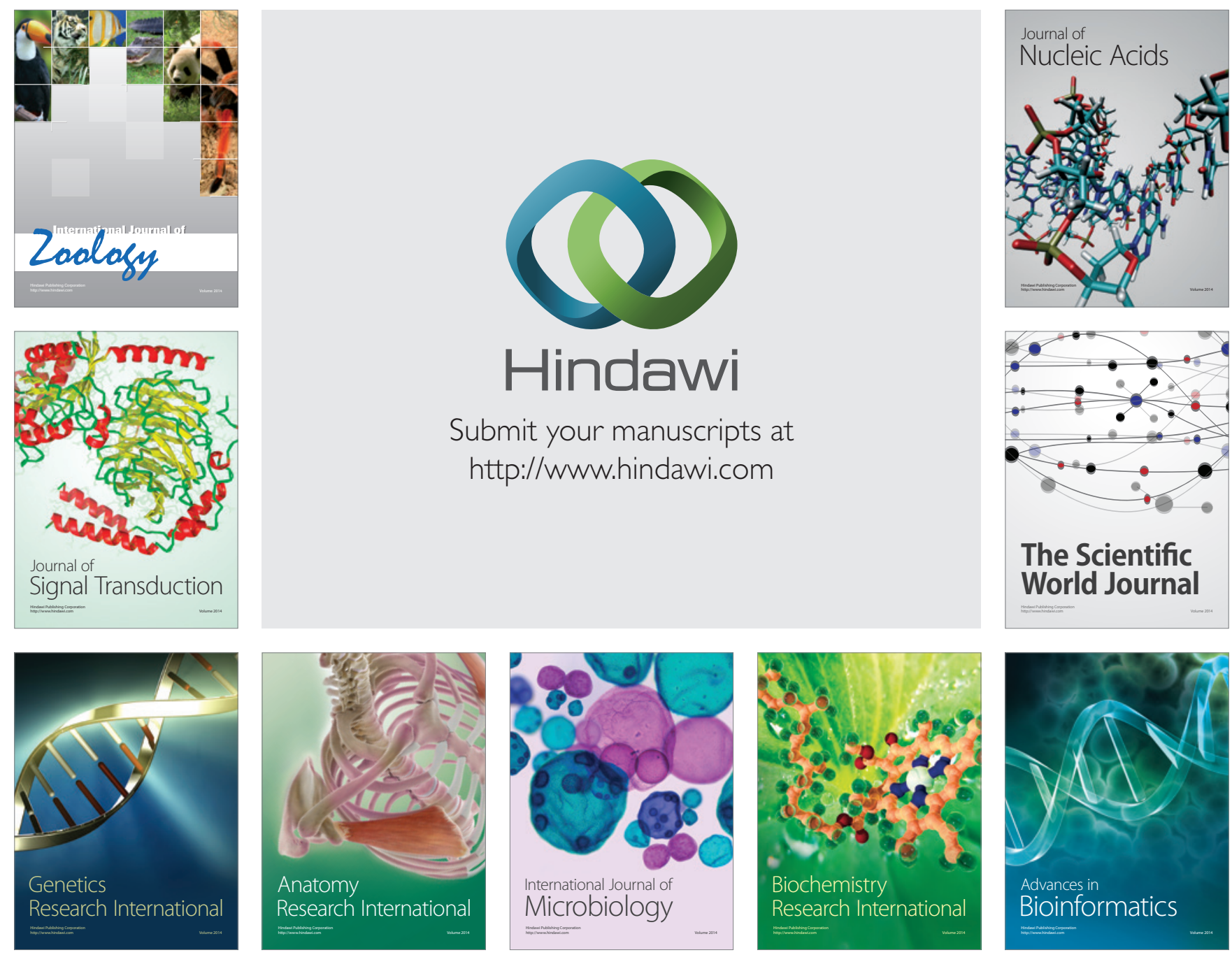

The Scientific World Journal
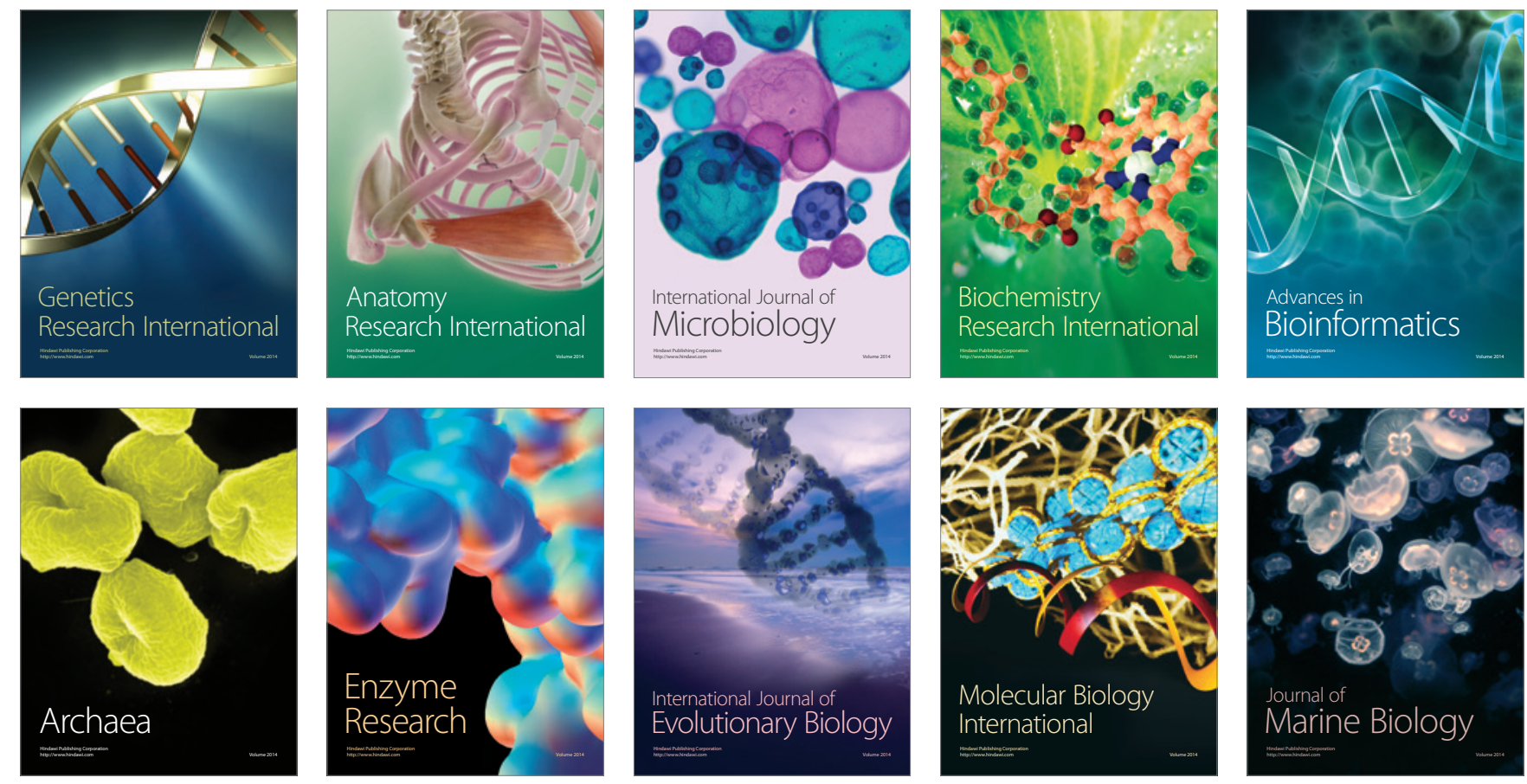